\title{
A REINVENÇÃO DO CARNAVAL NA EXTENSÃO PROFANA DA FESTA DE NOSSA SENHORA DA AJUDA NA CIDADE DE CACHOEIRA, NO RECÔNCAVO BAIANO
}

Janio Roque Barros de Castro (UNEB)

Na cidade de Cachoeira, na região do Recôncavo baiano, o carnaval deixou de acontecer nas ruas e em um tradicional clube da cidade no primeiro trimestre do ano; no entanto, a folia e a musicalidade carnavalesca passaram a fazer parte da extensão profana da festa de Nossa Senhora da Ajuda na primeira quinzena de novembro, como prática festiva reinventada. No presente trabalho analisa-se a dinâmica espacial e sociocultural da festa de Nossa Senhora da Ajuda nas ruas de Cachoeira, buscando compreender os elementos e práticas carnavalescas no contexto desse evento festivo. Para isso, analisaram-se arquivos de jornais, revistas, fotos antigas e entrevistaram-se pessoas envolvidas com as principais festas populares locais. A pesquisa revelou que muitas práticas brincantes e parte da musicalidade carnavalesca de Cachoeira foram reinventadas no contexto de outras festas populares, como a de Nossa Senhora da Ajuda.

FESTA DA AJUDA, CARNAVAL, CACHOEIRA.

CASTRO, Janio Roque Barros de. A reinvenção do carnaval na extensão profana da festa de Nossa Senhora da Ajuda na cidade de Cachoeira, no Recôncavo Baiano. Textos escolhidos de cultura e arte populares, Rio de Janeiro, v.9, n.1, p. 153167, mai. 2012. 


\section{THE REINVENTION OF CARNIVAL IN THE PROFANE EXTENSION OF NOSSA SENHORA DA AJUDA'S PARTY IN THE CITY OF CACHOEIRA, IN THE RECÔNCAVO BAIANO}

Janio Roque Barros de Castro (UNEB)

In the town of Cachoeira, in Bahia's region of Recôncavo, carnival events no longer happens on the streets nor in a traditional city club in the first quarter of the year; instead, the revelry and carnival musicality are now part of the profane extension of the party of Nossa Senhora da Ajuda, in the first half of November, as reinvented festive practices. In this paper we analyze the spatial and sociocultural dynamics of the Festa da Nossa Senhora da Ajuda on the streets of Cachoeira, trying to understand elements and carnival practices in the context of this festive event. To do so, we analyzed the archives of newspapers, magazines, old photos and we interviewed people involved in the major local festivals. The survey revealed that many reveler practices and part of the carnival musicality of $\mathrm{Ca}$ choeira were reinvented in the context of other popular festivals such as Nossa Senhora da Ajuda.

FESTA DA AJUDA, CARNIVAL, CACHOEIRA.

CASTRO, Janio Roque Barros de. A reinvenção do carnaval na extensão profana da festa de Nossa Senhora da Ajuda na cidade de Cachoeira, no Recôncavo Baiano. Textos escolhidos de cultura $e$ arte populares, Rio de Janeiro, v.9, n.1, p. 153167, mai. 2012. 


\section{INTRODUÇÃO}

A cidade de Cachoeira é conhecida tanto por seu conjunto arquitetônico, tombado como patrimônio histórico nacional, quanto pela riqueza de seu patrimônio intangível, que expressa elementos da diversidade cultural brasileira recriados ao longo do tempo. Em seu rico calendário festivo destacam-se as festas religiosas do catolicismo oficial e popular, as manifestações de matriz afro-brasileiras, como os cultos candomblecistas, e aquelas que transitam entre as duas matrizes culturais. A referida cidade apresenta festas importantes, como a de Nossa Senhora da Boa Morte, que atrai turistas internacionais e que transita sincreticamente da matriz afro-brasileira para o catolicismo oficial e popular. Como o carnaval se insere nesse contexto tão rico e diversificado de eventos festivos que transitam da dimensão do sagrado para o desregramento profano?

Das várias manifestações festivas da cidade de Cachoeira a extensão profana da festa de Nossa Senhora da Ajuda é uma das mais peculiares. Existem as celebrações litúrgicas que ocorrem no âmbito da Igreja, como novenas e missas, e uma folia profana no entorno. A capela de Nossa Senhora da Ajuda foi construída no final do século XVI e início do XVII nos arredores do engenho de açúcar que deu origem a uma nucleação urbana incipiente chamada de Vila de Nossa Senhora do Rosário do Porto da Cachoeira. A capela da Ajuda tem significado simbólico como marco zero do surgimento da cidade, sagrado na dimensão do catolicismo oficial e popular, mas também na dimensão profana, posto que a festa da Ajuda, cuja parte religiosa teve início no período colonial, se constitui em uma das mais populares da cidade.

Durante essa festividade as pessoas em grupos e fantasiadas circulam pelas ruas estreitas da cidade histórica, com faixas, adereços, máscaras, em clima de total irreverência e espontaneidade. Qual a relação entre essa festa e os carnavais cachoeiranos? Com a extinção dos carnavais de rua e nos clubes, tanto as marchinhas tradicionais do carnaval brasileiro quanto o embalo explosivo da axé music e do samba reggae baiano da atualidade, além de outros ritmos musicais, invadem as ruas de Cachoeira no transcurso do chamado "embalo da Ajuda". Milhares de pessoas se deslocam dançando pela área urbana. Pode-se afirmar então que o carnaval de Cachoeira ressurgiu no contexto da festa da Ajuda? No presente trabalho pretende-se analisar e compreender a extensão profana dessa ocorrência, buscando entender a inserção de elementos e práticas dos antigos e atuais carnavais de Cachoeira. Preliminarmente faz-se apreciação analítica das festas e dos sentidos do festejar 
para posteriormente analisarem-se os elementos carnavalescos presentes na tradicional festa da Ajuda.

\section{OS SENTIDOS DO FESTEJAR: UMA APRECIAÇÃO PRELIMINAR}

Qual ou quais os sentidos da festa? Qual o papel da festa como catarse coletiva? Como são concebidos os espaços festivos da contemporaneidade? $\mathrm{Na}$ concepção de Jean Duvignaud (1983), as festas se configuram como eventos que determinam uma ruptura da vida social caracterizada pela produção de um tempo e de uma forma de vivência momentaneamente alternativos ao cotidiano burocratizado e normatizado pelas regras de conduta social. Para a adesão a essa realidade paralela e efêmera, criam-se sujeitos ou grupos imaginários que podem ser seres míticos ou mesmo grandes personalidades; nesse contexto um operário assalariado pode transformar-se em príncipe ou rei, como lembra o antropólogo Roberto DaMatta (1990). Nessa perspectiva, a festa urbana se constituiria em metamorfose transitória de papéis sociais, consignando uma ruptura do cotidiano funcional, como destacam alguns autores.

Harvey Cox relaciona o que ele chama de homo festivus e homo phantasia à perspectiva mítica e destaca que a sociedade ocidental priorizou as abordagens marxistas e iluministas/positivistas:

Ora, nas centúrias mais recentes aconteceu algo que afetou a capacidade humana de festejar e fantasiar. Nossa civilização ocidental enfatizou demais o homem operário (Lutero e Marx) e o homem como pensador (Tomás de Aquino e Descartes), e se atrofiaram as faculdades celebrativas e imaginativas do homem (cox, 1974, p. 17).

Jean Duvignaud (1983) enfatiza que as noções de funcionalidade, utilidade e o espírito de rentabilidade que caracterizam o Ocidente industrializado se constituíram nos principais óbices para a compreensão da festa em todos os seus aspectos e escalas. Para o autor em tela, existem as festas de participação e de representação; enquanto aquelas congregam a comunidade, estas separam os protagonistas da trama festiva e os espectadores.

Harvey Cox (1974, p. 28-29) destaca a importância da festa como "válvula de escape" e como forma de imiscuir o aspecto lúdico na rotina cotidiana:

A festividade é, pois, um período de tempo reservado para a expressão plena do sentimento. Consiste dum irredutível elemento de prodigalidade, dum viver intensamente. A experiência o com- 
prova; traz alegria, o que, aliás, explica porque felicitamos aos outros em dias festivos, e consideramos bem sucedida uma festa em que todos se divertiram bastante. Sendo a festividade uma coisa que se faz por sua própria causa, propicia-nos breves férias das tarefas diárias, e uma alternância sem a qual seria insuportável a vida. Por sua vez, há certas coisas que não constituem festividade.

Contrapondo-se a Henry Lefebvre (1991a e 1991b), que faz uma crítica ao escalonamento tradicional da vida, promovendo um hiato entre o lazer, a festa e o cotidiano, Harvey Cox enfatiza a necessidade do homem funcional de participar da trama festiva como evento alternativo dissociado das práticas cotidianas, ou seja, a festa de acordo com essa leitura teria o papel de diminuir as eventuais tensões pela excessiva funcionalização, formalização e burocratização do homem moderno. Nessa linha de pensamento, Johan Huizinga $(2005$, p. 25$)$ enxerga na festa vários traços em comum em relação ao jogo:

Existem entre a festa e o jogo, naturalmente, as mais estreitas relações. Ambos implicam uma eliminação da vida quotidiana. Em ambos predomina a alegria, embora não necessariamente, pois também a festa pode ser séria. Ambos são limitados no tempo e no espaço. Em ambos encontramos uma combinação de regras estritas com a mais autêntica liberdade.

Lefebvre (1991a) destaca o fato de que as fadigas da vida moderna tornam indispensáveis o divertimento; critica, no entanto, a segmentação que separa de forma geral a festa e o lazer do cotidiano. Nas décadas que sucederam a publicação do livro de Harvey Cox, notou-se que o hiato entre festas e trabalho cotidiano se manteve, considerando-se a prevalência do segundo. Sobre a relação entre as festas e o jogo proposta por Huizinga, pode-se afirmar que a racionalização reguladora dos eventos festivos espetacularizados da contemporaneidade intensificaram a normatização de muitas festas populares. Michel Maffesoli (1996) destaca, no entanto, que o tempo livre não é mais forçosamente o mero momento de recuperação do ritmo do trabalho imposto, conforme análise de alguns pensadores da teoria social crítica, mas também não se limitaria a ser um produto comercializado; trata-se de totalidade que abarca os dois aspectos levantados pelo autor. Maffesoli (1996) propõe o conceito de socialidade para integrar análises de parâmetros tais como o sentimento, a emoção, o imaginário, o lúdico, que estão diretamente relacionados ao lazer festivo contemporâneo como contraponto de uma racionalização mecânica excessiva da vida social. 
As festas populares se constituem em importante manifestação cultural que pode ter sua origem em algum evento sagrado, social, econômico ou mesmo político do passado e constantemente passam por processos de recriações e atualizações; como destaca Paul Claval (1999), a cultura, como herança transmitida, pode ter sua origem em um passado longínquo, porém não se constitui em um sistema fechado, imutável de técnicas e comportamentos. Essa concepção de cultura como sistema aberto permite ao pesquisador compreender o dinamismo de algumas manifestações culturais que preservam importantes elementos como ponte entre o passado, o mito áurico fundador e o presente. Para que ocorram as mudanças, transformações e reinvenções das práticas culturais, os contatos são fundamentais, como lembra Claval (1999), e, nesse aspecto, notou-se intensificação das formas de comunicação e transmissão de informação nas últimas décadas. Por outro lado, o viés mercadológico e espetacular de algumas festas do presente desvincula a relação entre o ato de festejar e a rememoração, o conhecimento histórico, um mito fundador ou mesmo uma prática de reatualização, como destacam alguns autores, Mircea Eliade (1992) e Luís da Câmara Cascudo (1969) entre eles. O enfoque lúdico-cultural, eivado de simbolismo, se diferencia da prática festiva como entretenimento efêmero, assentado no lazer e na diversão, como ressaltou Hannah Arendt (2002), constituindo-se fundamentalmente prática presencial que, em muitos aspectos, realça o passado como um pano de fundo ou na perspectiva da estetização do espaço festivo. Evidentemente que não se defende neste trabalho a manutenção de práticas festivas essencialistas, determinadas por suposta aura que as mantenha imutáveis ao longo do tempo; a sociedade é dinâmica, por isso o ato e os significados do festejar se diferenciam ao longo do tempo. As reflexões sobre a diferença entre as festas de rememoração, com fortes vínculos com práticas do passado, e as festas de entretenimento, cuja finalidade é promover o lazer, a diversão ou determinada celebração do presente, têm o objetivo de apresentar uma contextualização de algumas facetas da prática festiva do povo brasileiro.

\section{O CARNAVAL DE RUA DE CACHOEIRA: EXTINTO OU REINVENTADO?}

No passado, a cidade de Cachoeira já realizou carnavais tradicionais com mascarados, confetes, serpentinas, cordões, exibicionismos de rua, bailes fechados em um clube chamado Associação Desportiva Paraguaçu, entre outras modalidades de diversão. A partir dos anos 60 a tradição do carnaval de rua foi 
declinando progressivamente. Após esse período realizaram-se alguns carnavais fora de época, na Bahia denominados micaretas.

Até meados dos anos 70 o carnaval de Cachoeira, que acontecia no primeiro trimestre do ano, e a festa de Nossa Senhora da Ajuda, em novembro, eram as festas mais expressivas em termos de apropriação do espaço público e de capacidade de mobilização da cidade. O carnaval, que acontecia na rua em clima de irreverência, criatividade e de valorização do caráter inventivo dos foliões, foi retirado do calendário cultural da cidade à medida que foi crescendo o poder "arrebatador" do megacarnaval de Salvador.

Não se pode falar em fim do carnaval de Cachoeira, mas em rearranjo no calendário festivo da cidade, que retirou essa importante manifestação do primeiro trimestre do ano recolocando-a no mês de abril com o nome de micareta. A principal diferença entre o carnaval tradicional e a micareta é que nesta última o trio elétrico exerce maior fascínio como objeto que direciona e centraliza a dinâmica da massa festiva. Apesar de as grandes micaretas realizadas no final dos anos 70 apresentarem expressivo magnetismo lúdicofestivo regional, esse evento deixou de ser realizado.

No dia 13 de março, quando se comemora a emancipação política de Cachoeira, os gestores públicos municipais costumam montar um palco na Praça da Aclamação, no Centro histórico, nas proximidades da Câmara municipal, e nele se apresentam bandas musicais, cantores e as filarmônicas locais homenageando a cidade. Entre promover um carnaval em fevereiro em concorrência direta com Salvador ou uma micareta em data neutra, optou-se pelos investimentos nas festas que se realizam em datas significativas, seja por questões de ordem cívica (13 de março) ou religiosa (festa de Nossa Senhora da Ajuda, em novembro). A data cívica mais importante de Cachoeira é o 25 de junho, quando se comemora a resistência daquela cidade à colonização portuguesa através da delimitação do território livre do domínio de Portugal após a Câmara de Cachoeira proclamar dom Pedro I como príncipe regente do Brasil, antecipando assim o histórico grito de independência em 7 de setembro de 1822. Instalou-se naquela cidade uma junta provisória responsável pela administração da província e em seguida o governo provisório da Bahia. A comemoração do aniversário da cidade e as homenagens ao suposto "heroísmo patriótico" de Cachoeira evidenciam claramente que ali se mesclam festas populares e civismo. O supostamente extinto carnaval local se teria diluído processualmente nessas comemorações cívicas e em outras festas populares?

Tanto os carnavais quanto as micaretas eram animados por trios elétricos que se concentravam principalmente na Praça da Aclamação devido 
às dificuldades de circulação em uma cidade com ruas estreitas. A massa festiva se estendia até as praças Teixeira de Freitas e 25 de Março. Notadamente nos anos 60, o trio elétrico Primavera era bastante respeitado e motivo de orgulho porque era da cidade, ou seja, no período carnavalesco oficial ou fora de época, Cachoeira gozava de uma relativa autonomia em relação à máquina/objeto de difusão da sonoridade que ainda desperta enorme fascínio no público. No entanto, na micareta de 1980 o então famoso trio elétrico Tapajós, que animava os carnavais de Salvador, exerceu a centralidade lúdico-festiva, visual e estética daquela festa popular e percorreu algumas ruas da cidade a despeito dos limites físicos dos arruamentos antigos e do tamanho do veículo.

Em 1980, os principais espaços públicos da folia carnavalesca eram as praças da Aclamação, 25 de Junho e Teixeira de Freitas, que são contíguas. Nesse ano, ocorreu uma grande enchente em Cachoeira que causou enormes prejuízos; o Rio Paraguaçu transbordou e inundou a cidade. Segundo alguns moradores locais mais antigos, muita gente buscou nas festividades populares conforto para esquecer os infortúnios das cheias.

Em Cachoeira a folia carnavalesca começava no final da tarde porque os bailes na Associação Desportiva do Paraguaçu eram elitizados e seletivos, e quem fazia o carnaval era o povão nas praças e em artérias viárias do entorno, não havendo, portanto, preocupação com a sincronização temporal entre os bailes da Associação Desportiva e as festa de rua. Havia, entretanto, implícito interesse por parte de alguns apreciadores da festa fechada em também participar de forma efetiva da folia no espaço público, o que determinou que os bailes fossem realizados a partir das 22 horas.

Em relação à musicalidade, a influência das marchinhas tradicionais, veiculadas nacionalmente, nos carnavais dos anos 50 e 60 era muito forte; todavia, nas micaretas do finais dos anos 70 já se notavam as influências da musicalidade e da sonoridade baiana da época.

Cachoeira foi uma das pioneiras na promoção de festas juninas espetacularizadas no espaço urbano. A primeira experiência dessa natureza ocorreu em 1972 por iniciativa da Empresa de Turismo da Bahia - Bahiatursa, estando a cidade recém-tombada como patrimônio nacional. Desde a primeira edição a festa é realizada na Avenida Virgílio Reis (Rua do Cais) que margeia o Rio Paraguaçu, aproveitando-se de todo o simbolismo cultural de uma feira livre que acontece na orla fluvial de Cachoeira, chamada de Feira do Porto, em que no passado se comercializavam produtos juninos típicos (CASTRO, 2008). Houve um curto período de sincronização temporal do carnaval e a posterior organização das micaretas e a realização das festas juninas na Feira do Porto, 
ou seja, a retirada das primeiras manifestações festivas não foi determinada pelo surgimento e consolidação da segunda. A partir dos anos 90, entretanto, as festas juninas de Cachoeira organizadas pela prefeitura passaram a mesclar em sua matriz programática o chamado forró tradicional e o são João cultural, em que se apresentavam grupos culturais locais com axé music e o chamado forró eletrônico, o que para alguns foliões significou a "carnavalização" ou a "micaretarização" do são João.

Esse hibridismo de ritmos musicais determina também diversificação na performance dançante e constitui indicativo de que o carnaval e as micaretas foram cooptados pelas festas juninas na sua dimensão urbana espetacular. Pode-se afirmar, aliás, que o carnaval e a micareta de Cachoeira, independentemente da intencionalidade gestionária de suas municipalidades, se fragmentaram e se desterritorializaram espaçotemporalmente e se reterritorializaram em outras manifestações festivas de rua importantes no calendário local: as festas juninas e a parte profana da festa de Nossa Senhora da Ajuda, no chamado "embalo da Ajuda". Nesse evento desfilam mascarados e "cabeçorras" que são pessoas que se fantasiam de bonecos, utilizando geralmente roupas com cores chamativas e cabeça grande, desproporcional ao corpo. O indivíduo representado pode ser anônimo, alguém conhecido da cidade ou mesmo pessoas famosas ou políticos que são satirizados. Outros personagens que surgem na festa da Ajuda são os mandus, que chamam a atenção, sobretudo dos visitantes. Mandu é fantasia masculina caracterizada por adereço circular envolto em tecidos e fitas usado na cabeça, escondendo o rosto; assim desfilam os indivíduos pelas ruas da cidade ao som de batucadas, músicas tradicionais e cânticos geralmente de matriz afro-brasileira. O nome dessa modalidade de expressão festiva se deve ao jeito desengonçado e irreverente dessa fantasia folclórica. Assim como em Minas Gerais a palavra "trem" é utilizada para designar uma coisa cujo nome não se sabe, a palavra mandu faz parte do vernáculo baiano para denominar objeto ou evento considerado estranho, diferente, de difícil categorização. Algumas pessoas consideram o mandu um espírito ou uma entidade. São, enfim, diferentes as leituras dessa importante manifestação cultural.

Antigamente, na parte profana da festa da Ajuda, desfilavam ternos temáticos, como os grupos das cozinheiras e das gauchetes (homens vestidos de mulher), entre outros, e se inseriam no cortejo lúdico alguns folguedos tipicamente nordestinos, como o trança-fita, que se apresentava na Feira do Porto durante os festejos juninos. A festa de Nossa Senhora da Ajuda apresentou ao longo do século XX e nos primeiros anos do XXI pulsante 
dinâmica cultural, com o desaparecimento e o ressurgimento de diversas manifestações culturais que expressam diversidade local/regional.

\section{RESSURGIMENTO/REINVENÇÃO DO CARNAVAL DE CACHOEIRA NO CONTEXTO DO “EMBALO DA AJUDA"}

A festa de Nossa Senhora da Ajuda homenageia a santa que teve a primeira igreja edificada em Cachoeira entre os séculos XVI e XVII e é comemorada na dimensão do sagrado assim como a festa de santa Cecília, ambas no mês de novembro. Durante muitas décadas houve acirrada rivalidade entre os participantes dessas duas festas religiosas: as pessoas ligadas à Filarmônica Lira Ceciliana do bairro do Monte rivalizavam com os músicos e demais pessoas ligadas à Filarmônica Minerva Cachoeirana, do bairro da Ajuda, que alguns consideravam elitizada.

As escaramuças e animosidades entre as duas filarmônicas podem ser relacionadas a fatores de ordem política, econômica e cultural do passado e que se estenderam por muitas décadas. Há relatos de agressões físicas; os ânimos se exaltavam notadamente quando a rivalidade era potencializada por questões de ordem política. No espaço urbano de Cachoeira a Lira Ceciliana e a Minerva Cachoeirana construíram historicamente sua territorialidade estruturada a partir de território material, tangível, que corresponde ao prédio de suas sedes próximas da Igreja do Monte, na Rua Monsenhor Tapiranga e na Praça Rio Branco, respectivamente. Essa territorialidade tem natureza difusa e fragmentária uma vez que os integrantes de cada filarmônica fazem de sua casa uma extensão de seu grupo musical.

As retretas, que são as exibições públicas das filarmônicas, aconteciam em datas cívicas importantes ou em eventos como as festas juninas urbanas; elas podem ser consideradas tanto o espaço-tempo da integração quanto, paradoxalmente, o ápice da rivalidade territorial exercitada na musicalidade, e às vezes extremada com agressões físicas ou verbais no espaço público, como já ocorrido no passado nas zonas de tensão territorial. A repulsa mútua dos integrantes da Lira Ceciliana e da Minerva Cachoeira criava atmosfera de autoexclusão festiva, levando o participante de uma filarmônica a não participar de festas promovidas pela rival.

Depreende-se dessa forma que o espaço urbano de Cachoeira, no tempo festivo, pode ser considerado tanto espaço de integração e horizontalidade das relações afetivas quanto espaço de prática e atualização de correlações de forças determinadas pelo desejo de exercer relativa hegemonia no lugar, 
seja por iniciativa individual como nas fantasias criativas da festa da Ajuda que disputam a atenção dos expectadores, seja como prática coletiva a exemplo dos antigos blocos carnavalescos e das micaretas. É importante destacar que as filarmônicas de Cachoeira tiverem grande importância na história tanto cultural quanto política da cidade; muitas celeumas e escaramuças eram alimentadas pelo ativismo sociopolítico e ideológico, e emolduradas por elementos socioculturais.

Considerando-se que a cidade de Cachoeira apresenta várias modalidades de festas populares, por que a musicalidade e as performances dançantes típicas dos carnavais brasileiros se concentram na festa da Ajuda? Para responder a essa questão deve-se transitar brevemente pelos principais eventos festivo de Cachoeira. No mês de janeiro, ocorrem pontualmente as festas em homenagens aos Santos Reis em algumas residências; mesclamse o religioso e o lúdico em eventos discretos. Em março, no aniversário da cidade, há predomínio da música baiana, notadamente a axé music. Em junho, as megafestas juninas priorizam o forró, eletrônico e tradicional. Em agosto acontece a festa de Nossa Senhora da Boa Morte, que é um importante evento religioso da cidade, mas que apresenta natureza assentada em ritualística religiosa na interface de cultos de matriz afro-brasileira e católica. As outras festas importantes da cidade, como as homenagens aos santos gêmeos são Cosme e são Damião e a festa da padroeira, apresentam viés religioso bem mais expressivo do que sua extensão profana. A festa da Ajuda se diferencia nesse contexto porque é evento que cresceu e ganhou as ruas em clima carnavalizado de irreverência, alegria e criatividade.

A festa em louvor a Nossa Senhora do Rosário, padroeira da cidade, é outra manifestação religiosa importante ligada ao catolicismo oficial que acontece no mês de outubro, mas que atualmente se limita à dimensão do sagrado. Existem outras manifestações religiosas, como a festa do Divino Espírito Santo, que ocorre no mês de maio e na qual os organizadores procuram estabelecer uma ponte entre os elementos do catolicismo popular, expresso através de práticas como a coroação do imperador, e o catolicismo oficial, representado tanto do ponto de vista da materialidade (Igreja Matriz) quanto através das práticas litúrgicas romanizadas. Diferentemente da festa da padroeira, a festa de Nossa Senhora da Ajuda nos últimos anos temse notabilizado por sua extensão profana, com a organização de um grande bloco formado por mascarados, mandus, cabeçorras, pessoas fantasiadas de várias formas criativas que desfilam pelas principais ruas da cidade, formando o chamado "embalo da Ajuda" e dançando freneticamente marchinhas 
carnavalescas tradicionais, ritmos cadenciados que se assemelham ao das escolas de samba do Rio de Janeiro e o tradicional samba do Recôncavo. (Figura 1)

Nesse contexto de sonoridade híbrida surgem sucessos recentes da axé music baiana, em meio a marchinhas de antigos carnavais, samba de roda, frevo, merengue e outros ritmos. Trata-se não de desenfreada mistura de diferentes musicalidades, mas de uma explosão de sonoridades que se aproximam, se complementam, se contrapõem, destoam, fazendo os grupos de foliões circularem por várias ruas da cidade de forma errante ou direcionada, formando uma massa festiva concentrada ou se dissipando abruptamente para formar dezenas de grupos esparsos.

A festa da Ajuda inicialmente era elitizada; aos poucos se popularizou. Recentemente o "embalo da Ajuda" tem apresentado itinerário mais difuso; os blocos percorrem diferentes ruas e esporadicamente se encontram na área urbana da cidade histórica. A parte profana da festa de Nossa Senhora da Ajuda tem início no final do mês de outubro, quando grupos de pessoas com carroças, grupos dançantes e carros de som formam o "bando anunciador" ou "pregão", que revela parte da diversidade dessa importante manifestação cultural. Tratase de uma modalidade de comissão de frente que desfila pelas principais ruas da cidade para anunciar a proximidade da festa, que se inicia nas semanas subsequentes, o que corresponde à primeira quinzena de novembro. No "bando anunciador" divulga-se também a programação do evento.

Atualmente ainda existe a parte religiosa da festa da Ajuda. Na extensão profana forma-se festa com participação de pessoas de outros municípios, embora o evento seja considerado predominantemente local. A festa da Ajuda, que teve seu auge no passado e que já passou por crises que ameaçaram sua existência, é hoje considerada patrimônio cultural imaterial de Cachoeira apesar das críticas relacionadas ao que algumas pessoas consideram excessiva "profanatização" de festividade cuja gênese está relacionada à aura da dimensão do sagrado.

Além da crítica a uma suposta dessacralização, algumas pessoas defendem a tese de que a festa da Ajuda era mais politizada no passado quando se exibiam cartazes irreverentes e de crítica social; entretanto, a estilização, estetização e divulgação dos elementos e práticas de matriz afro-brasileira em uma manifestação festiva da dimensão do "embalo da Ajuda", que acontece em uma cidade tombada como patrimônio nacional, não deixam de ser indicação de ativismo político assentado na questão étnico-cultural, mesmo que alguns desses personagens que protagonizam a trama festiva desconheçam a 


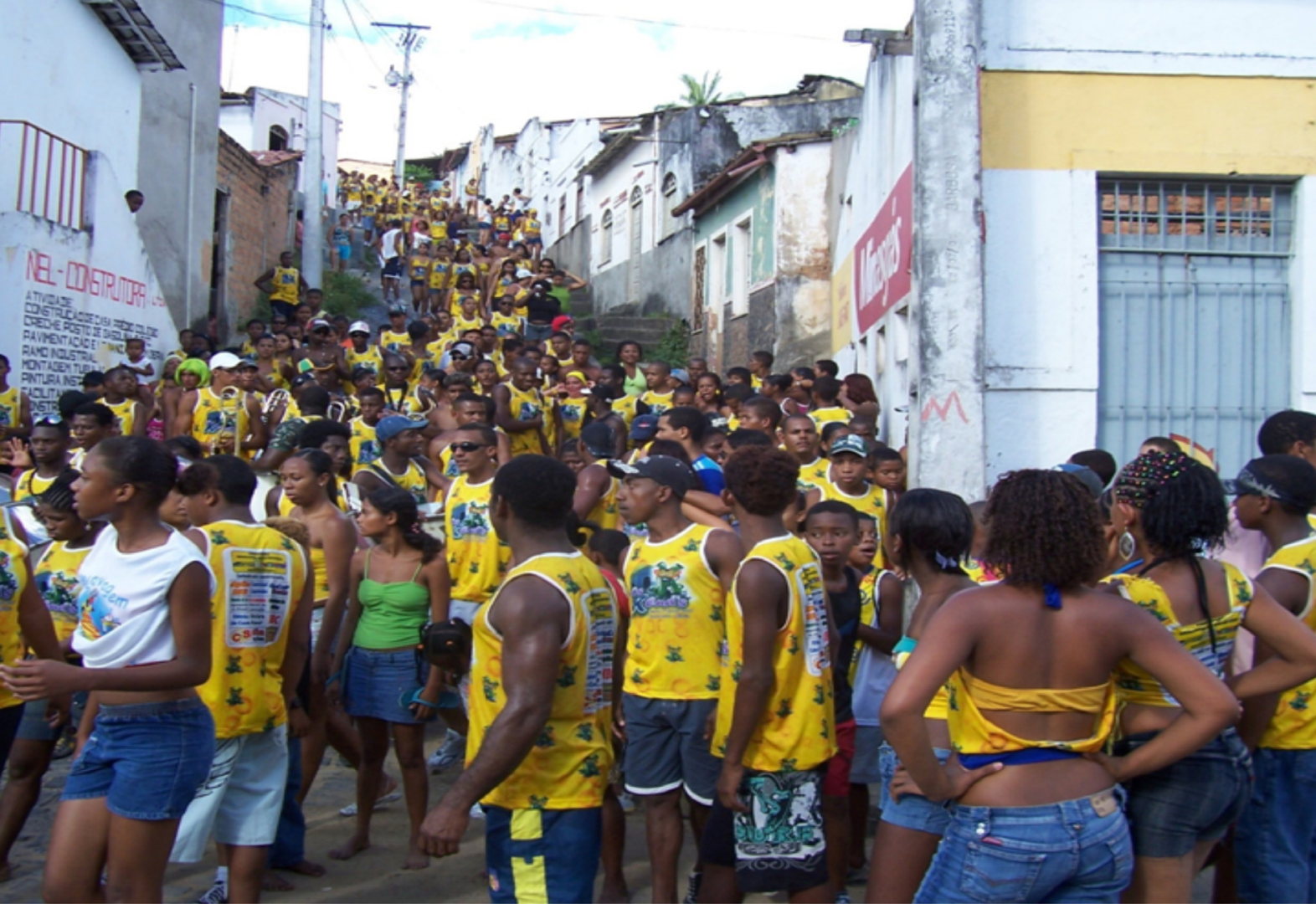

Figura 1: Multidão acompanha o embalo da Ajuda pelas ruas históricas de Cachoeira Foto do autor, novembro de 2007

politização de suas práticas. Aspectos da cultura afro-brasileira como as danças, roupas, religiosidade, práticas brincantes aparecem de forma explícita no espaço público de Cachoeira durante a festa da Ajuda. É importante destacar que questões como a discriminação e a falta de visibilidade para a cultura negra são recorrentemente discutidas em âmbito acadêmico; nesse contexto as festas populares serviriam para divulgar algumas facetas socioculturais de Cachoeira e do Recôncavo baiano e, ao mesmo tempo, para expressar uma crítica em um evento lúdico-festivo de elevada concentração de pessoas.

O que se pode afirmar é que a festa da Ajuda passou por momentos de ampliação territorial, encolhimento e novamente ampliação, e, ao longo desse processo sociocultural e espacial, se transformou agregando novas dinâmicas, como a mobilidade territorial em uma dimensão profana. A festa da Ajuda atualmente, após enfrentar crises, decréscimo e críticas, é manifestação cultural em franco processo de revitalização e tem sua importância reconhecida por moradores de Cachoeira, pela municipalidade e por documentos institucionais de planejamento turístico, como o Plano de Desenvolvimento Integrado do Turismo Sustentável - PDITS, elaborado pelo governo do estado da Bahia. 


\section{REFLEXÕES FINAIS}

Diante da diversidade estética, artística e das formas de dançar no embalo da Ajuda, pode-se afirmar com segurança que o carnaval ou as micaretas de Cachoeira foram extintas? Discordo desse viés saudosista e cartesiano no qual se fatiam os eventos socioculturais. Aquela forma de fazer carnaval em Cachoeira, no espaço público e na Associação Desportiva Paraguaçu foi parte de outro contexto temporal e que se desterritorializou como um todo contínuo e se reterritorializou de forma difusa, se redistribuindo espaçotemporalmente nas festas profanas em homenagem ao aniversário da cidade em março, nas festas juninas na orla fluvial e principalmente no "embalo da Ajuda".

Se por um lado as práticas brincantes dos foliões durante o "embalo da Ajuda" mesclando axé music baiana com pagodes sulistas se assemelham às micaretas, por outro, máscaras, bonecões e a diversidade cultural lembram, segundo alguns participantes idosos, os carnavais cachoeiranos do passado, dos entrudos, mascarados e serpentinas. Nota-se claramente um incessante processo de aceleração de contatos, influências, "contaminações" que hibridizaram festas populares de Cachoeira, como a da Ajuda; percebe-se esse metamorfismo na estética corpórea, na sonoridade, na musicalidade.

As práticas carnavalescas do passado misturam-se com outras, do presente. Dessa forma o folião não volta ao passado para vivenciar os carnavais de meados do século $X X$, nem vivencia exclusivamente a musicalidade e práticas dos carnavais da atualidade. Há incursões das festas do passado e do presente assim como há elementos e práticas dançantes de variados ritmos musicais de diferentes regiões do Brasil. Essa talvez seja a principal peculiaridade do "embalo da Ajuda".

As marchinhas mais lentas do passado mesclaram-se com estilos musicais atuais o que contribuiu para acelerar o deslocamento do "embalo da Ajuda" pelas ruas da cidade. Não se trata apenas de um carnaval fora de época, de uma micareta, nem mais uma extensão profana de festas religiosas; tratase de um evento festivo híbrido contemplando vários elementos que convidam o pesquisador a refletir conceitualmente acerca dos problemas que envolvem as ilações mecânicas e abruptas nas quais as palavras fim, término e extinção são recorrentemente utilizadas. No presente artigo propõe-se um eixo analítico menos abrupto e cartesiano e mais ponderado e contextualizado do ponto de vista sociocultural. 


\section{REFERÊNCIAS BIBLIOGRÁFICAS}

ARENDT, Hanna. Entre o passado e o futuro. Tradução de Mauro W. Barbosa. São Paulo: Perspectiva, 2002.

CASCUDO, Luís da Câmara. Folclore do Brasil: pesquisas e notas. Brasil/Lisboa: Fundo de Cultura, 1969.

CASTRO, J. Roque Barros de. Dinâmica territorial das festas juninas na área urbana de Amargosa, Cachoeira e Cruz das Almas: espetacularização, especificidades e reinvenções. Tese (Doutorado em Arquitetura e Urbanismo) - Universidade Federal da Bahia. 2008.

CLAVAL, P. Geografia Cultural: o estado da arte. In: CORRÊA, R. L. e ROSENDHAL, Z. (Orgs.) Manifestações da cultura no espaço. Rio de Janeiro: Eduerj, 1999.

COX, Harvey. A festa dos foliões. Tradução: Edmundo Binder. Petrópolis: Vozes, 1974.

DAMATTA, Roberto. Carnavais, malandros e heróis: para uma sociologia do dilema brasileiro. Rio de Janeiro: Guanabara Koogan. 1990.

DUVIGNAUD, Jean. Festas e civilizações. Tradução de L. F. Raposo Fontenelle. Fortaleza/Rio de Janeiro: UFCE/Tempo Brasileiro, 1983.

ELIADE, Mircea. O sagrado e o profano. Tradução de Rogério Fernandes. São Paulo: Martins Fontes, 1992.

HUIZINGA, Johan. Homo ludens. O jogo como elemento da cultura. Tradução de João Paulo Monteiro. São Paulo: Perspectiva, 2005.

LEFEBVRE, Henri. A vida cotidiana no mundo moderno. Tradução: Alcides João Barros. São Paulo: Ática, 1991a.

. O direito à cidade. Tradução de Rubens Eduardo Frias. São Paulo: Ed. Moraes, 1991b.

MAFFESOLI, Michel. No fundo das aparências. Tradução de Bertha Halpern Gurovitz. Petrópolis: Vozes, 1996.

Janio Roque Barros de Castro é professor adjunto da Universidade do Estado da Bahia e do mestrado em Cultura, Memória e Desenvolvimento, mestre em geografia e doutor em arquitetura e urbanismo pela Universidade Federal da Bahia. 
